\title{
TWO-MASS GYRO-PARTICLE AS THE TOOL FOR SUPERSONIC AEROELASTICITY ANALYSIS
}

\author{
SERGEY V. ARINCHEV \\ Bauman Moscow State Technical University (BMSTU) \\ 107005, 2-ya Baumanskaya street, 5/1, Moscow, Russian Federation \\ arinchev@inbox.ru
}

Key words: Supersonic Aeroelasticity, Gyro-Particle, Frequency Splitting

Summary. The proposed flutter interpretation is applicable to plasma aeroelasticity analysis. In this case it shall be possible to divide a particle in two, to generate two opposite electric charges and thus ionize the flow. The proposed two-mass gas gyro-particle has the elastic elements and the two pairs of multiple oscillation frequencies. The incident gas gyro-particles interact with the structural particles of the streamlined elastic body. The gas particles start to rotate and pulsate. The multiple oscillation frequencies of the gas particles split. The higher the vehile speed, the larger the gap between the oscillation frequencies of the gas particle. The structural resonance takes place, when the gas-particle pulsation frequency gets into the vicinity of an eigenfrequency of the elastic structure. This resonance is the flutter. Plasma is not considered here. This work is only a preparation step in this direction.

\section{INTRODUCTION}

Consider the elastic body in the high-speed supersonic flow. From one side, the front of the shock wave gets closer to the body surface. From another side, the turbulent frictional boundary layer of the body gets wider. Assume that these two quantities are commensurable ones. If plasma is available, then the shock wave starts to disintegrate, the flow medium starts to intermix [1,2]. Static equilibrium analysis [3,4] is not satisfactory to solve the flow-andstructure interaction problem. The clearly defined shock-wave-front surface shall be replaced with a specific contact-type vortex-induced formation with uncertain boundaries. The concept of the contact-type vortex-induced formation is introduced by O. Azarova [5]. Her work is available free in the Internet. Possibility of a vortex-type interpretation of the supersonic flow is proved in the work [6].

Nowadays the "piston" theory and its modifications are widely used for solving the supersonic aeroelasticity problem. The important results are obtained [7-9]. The well known vortex-element method [10-12] works properly in the incompressible-liquid medium. The particle approach specified in this issue provides the following calculation facilities: joint analysis of aerodynamic pulsations and oscillations of the elastic body, arbitrary structural- 
surface geometry in the incident flow, 3D-motion analysis, gas-compressibility assumption, refinement of the gas-pulsation character, particle disintegration, heating effects, etc. Each particle has its own repulsion-type force characteristic. By changing the force characteristic parameters the subsonic flow may be replaced with the supersonic one. The considered problem is the time-dependent Cauchy one with the given initial conditions.

The concept of the elementary gyro-particle is introduced in [13]. This report considers the so-called two-mass elastic gas gyro-particles with the given repulsion-type force characteristic. The particles are point masses $[14,15]$. The proposed particle takes the medium elasticity into account. Under the special conditions a separate two-mass particle can be disintegrated in two and thus ionize the incident flow. Each particle interacts with each one. The streamlined elastic body is also made of particles. They are the structural one-mass particles connected by springs. The gas particles interact with the structural ones. This interaction produces the so-called contact-type vortex-induced formation with intensive pulsations. The clearly defined shock-wave-front surface is not available.

The gas particle "rotation intensity" is associated with the its gyro-load parameter. If the gyro-load parameter is zero, then the particle eigenfrequencies are the multiple ones. The higher the gyro-load parameter, the larger the frequency gap. They are the frequencies of the gas pulsations. The system resonance takes place when a gas pulsation frequency gets into the vicinity of the eigenfrequency of the elastic body.

The problem-solution convergence rate (in the number of considered particles) is high $[15,16]$. Dozens (hundreds) of the particles are quite enough to illustrate the considered aeroelastic effects.

\section{DESCRIPTION OF THE TWO-MASS GAS GYRO-PARTICLE}

The two-mass gas gyro-particle is shown in Figure 1.

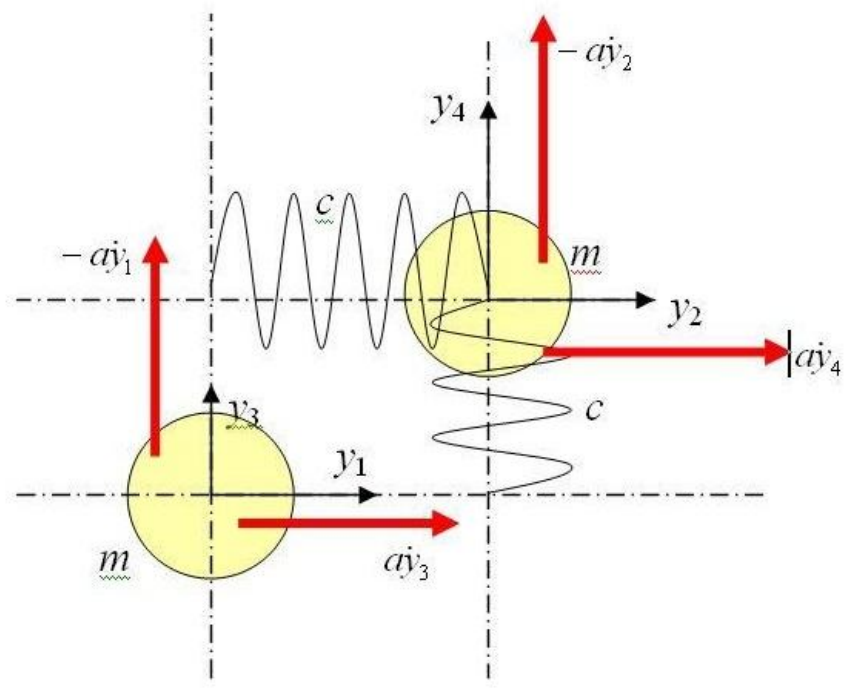

Figure 1: The two-mass gas gyro-particle 
The particle displacements are translational. Friction is not available. A separate particle (see Figure 1) move in compliance with its dynamics equations:

$$
\begin{aligned}
& -m \ddot{y}_{1}+c\left(y_{2}-y_{1}\right)+a \dot{y}_{3}=0 \\
& -m \ddot{y}_{2}-c\left(y_{2}-y_{1}\right)+a \dot{y}_{4}=0 \\
& -m \ddot{y}_{3}+c\left(y_{4}-y_{3}\right)-a \dot{y}_{1}=0 \\
& -m \ddot{y}_{4}-c\left(y_{4}-y_{3}\right)-a \dot{y}_{2}=0
\end{aligned}
$$

where:

$a-$ is the particle gyro-load parameter associated with its "rotation intensity".

Matrix $A$ of the gyro-load coefficients is the skew-symmetric one:

$$
A=\left[\begin{array}{cccc}
0 & 0 & a & 0 \\
0 & 0 & 0 & a \\
-a & 0 & 0 & 0 \\
0 & -a & 0 & 0
\end{array}\right]
$$

The particle characteristic eigenvalue equation takes the following form:

$$
\begin{gathered}
b_{0} \lambda^{8}+b_{2} \lambda^{6}+b_{4} \lambda^{4}+b_{6} \lambda^{2}=0 \\
b_{0}=m^{4} ; b_{2}=m^{2}\left(4 m c+2 a^{2}\right) ; b_{4}=4 m^{2} c^{2}+4 a^{2} m c+a^{4} ; b_{6}=4 a^{2} c^{2}
\end{gathered}
$$

If the gyro-load parameter $a=0$ (the particle is not "spinned up" yet), then $b_{6}=0$. In this case the particle has the two pairs of multiple eigenvalues and the two zero (solid-state) ones.

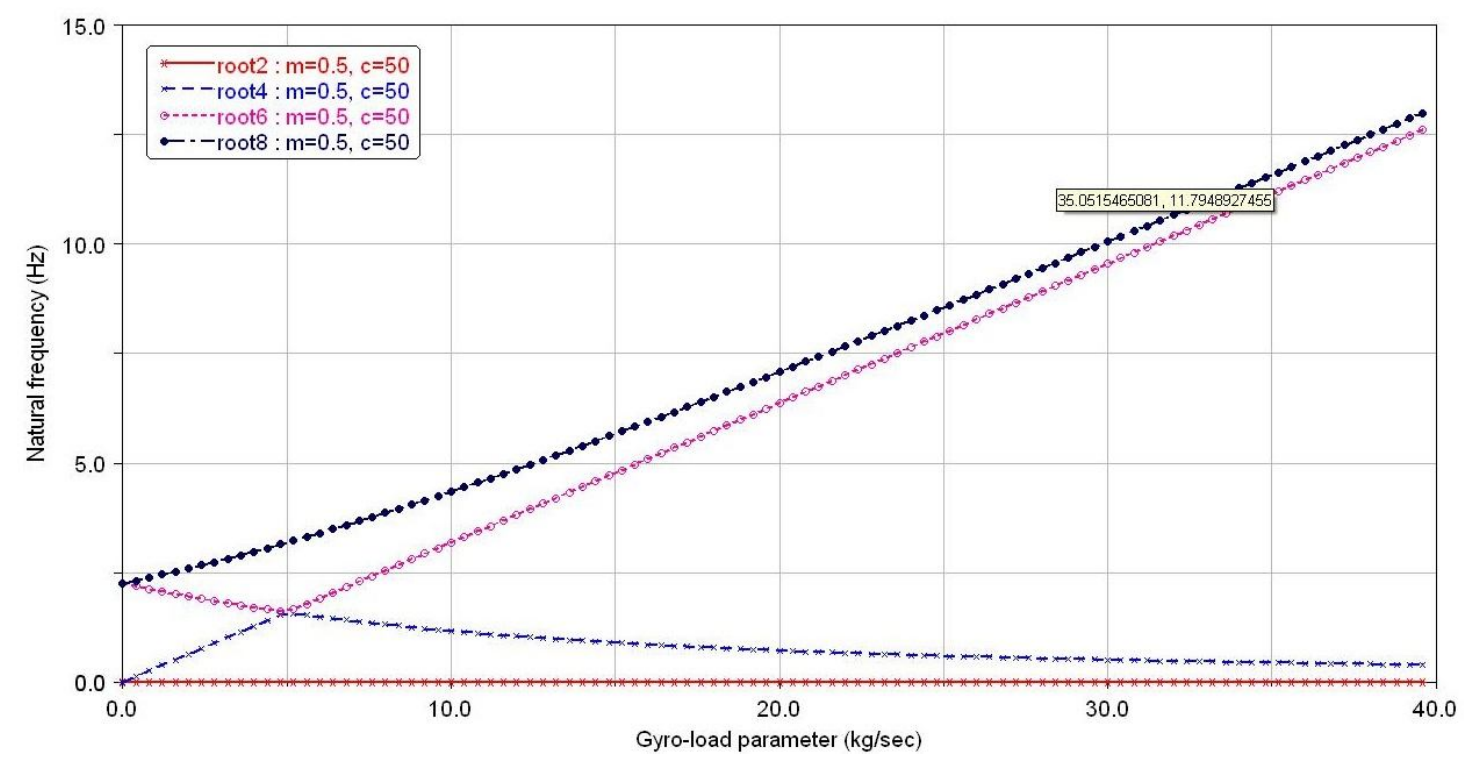

Figure 2: Splitting of the particle eigenvalues. Loss of one the two zero (solid-state) ones 


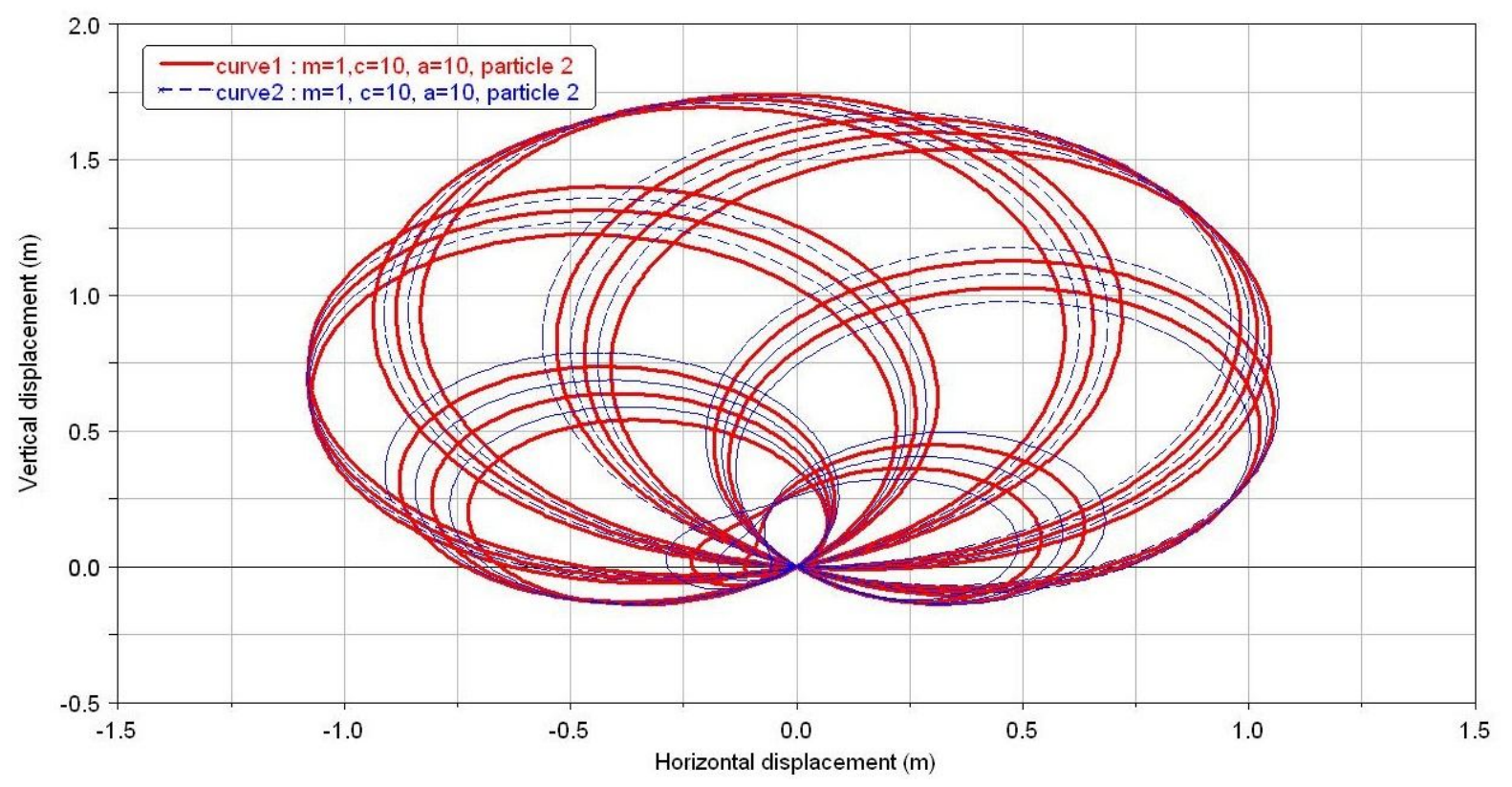

Figure 3: The particle pulsations induced by the unit impulse (4)

It is shown in Figure 2, that increase of the gyro-load parameter (associated with the particle "rotation intensity") leads: 1) to splitting of the particle eigenvalues, 2) to loss of one of the two zero (solid-state) ones.

Figure 3 specifies the typical pulsation trajectories of the subparticles of the two-mass gyro-particle in its phase plane. It is the dynamic response to the external unit impulse under the following initial conditions:

$$
y_{1}=\ldots=y_{4}=0 ; \dot{y}_{1}=1 ; \dot{y}_{2}=\dot{y}_{2}=\dot{y}_{3}=0
$$

One of the two zero (solid-state) eigenvalues is lost. So, displacements of the particle (as a solid body) are constrained.

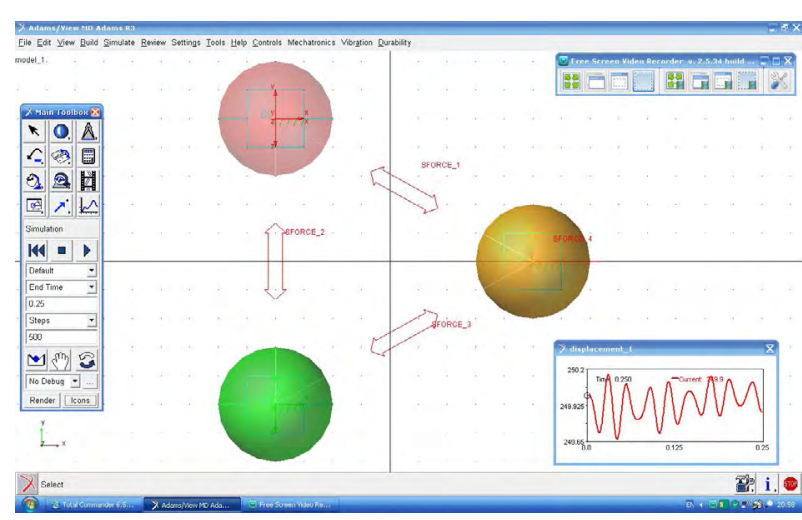

Figure 4a: The streamlined 3-mass elastic body
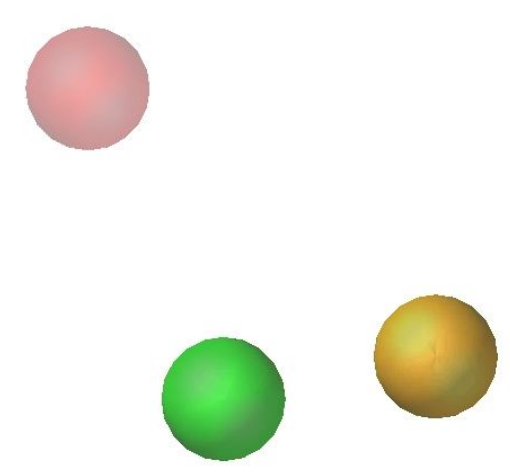

Figure 4b: The body $11.2 \mathrm{~Hz}$ eigenmode 
The report presents the simplified 2D-model of the dynamic interaction of the elastic body with the incident contact-type vortex-induced formation. Figure $4 a$ presents the elastic body. Initially it is the equilateral triangle. Its initial leg is $d_{1}$. The 3 structural particles (the $m_{1}$ point masses) are in its vertices. The structural particles are connected using the $c_{1}$ springs (red arrows in Figure $4 a$ ). The structural particles move translationally in the plane. They oscillate. Figure $4 b$ specifies one of the body eigenmodes. Its corresponding eigenfrequency is $11.2 \mathrm{~Hz}$.

The considered gas gyro-particle has two $m_{2}$ subparticles (see Figure 1): the main subparticle and the conjugate one. It is assumed that only the main subparticle is active. It takes part in all the interactions. The conjugate subparticle is passive. It just hangs on the main subparticle and hampers its motion. The conjugate subparticles are influenced by inertia forces, elastic springs and gyro forces. The subparticles are connected by the $c_{2}$ springs in the coordinate-wise manner.

\section{VORTEX CHARACTER OF THE PARTICLE MOTION}

The subparticle is a point mass. Its rotation is not available. Its motion is translation under the applied gyro forces. The response trajectory is a polyharmonic one. It has the vortex character. It is the superimposition of rotations (pulsations) in the phase plane. Highfrequency weak pulsations are superimposed by the low-frequency strong ones. (The particle numeration scheme is specified later in Figure 7).

The idea is that supersonic character of the flow is defined not by the streamlined-body linear velocity. It is defined by the incident-particle rotation intensity (by the value $a$ of the associated gyro-load parameter). That is why in all the considered examples the body linear velocity is always the same, but the gyro-load parameter $a$ is different. Figures $5 a-5 b$ show,

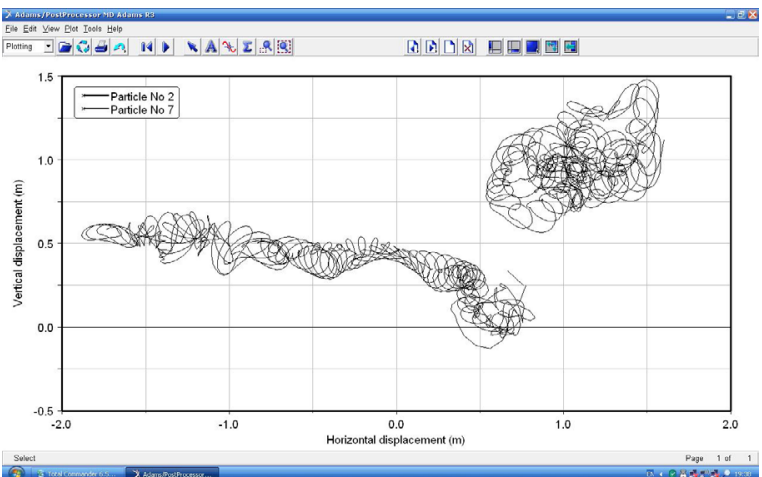

Figure 5a: Particles Nos.2-7, $a=20(\mathrm{~kg} / \mathrm{sec})$

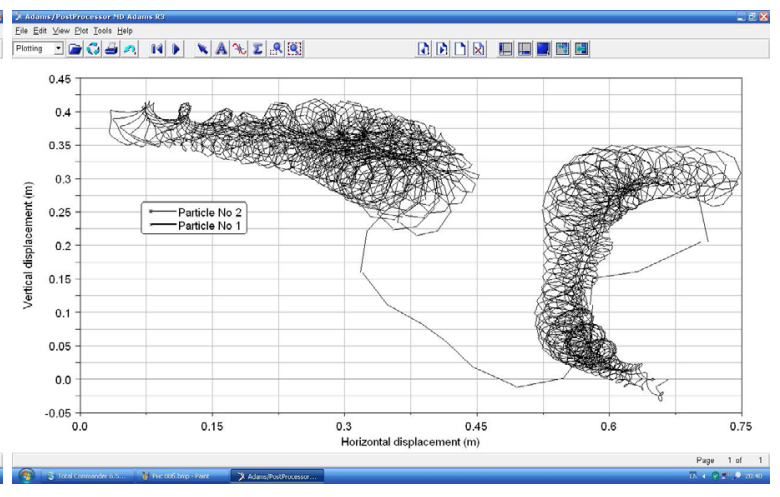

Figure 5b: Particles Nos.1-2, $a=50(\mathrm{~kg} / \mathrm{sec})$

that the higher the particle rotation intensity, the lower the particle pulsation amplitude, the greater the gap between the splitted frequencies.

To the first approximation, Mach number of the incident gas flow can be identified by comparing the considered vortex with the reference one. The reference O. Azarova supersonic vortex (corresponding to $M=1.89$ ) is shown in Figure $6 a$. The reference [5] is available free in the Internet. 
The vortex in Figure $6 b$ is obtained for $a=50(\mathrm{~kg} / \mathrm{sec})$. Compare the Figures $6 a$ and $6 b$. The considered vortex and the reference one are much alike. So, the gyro-load parameter $a=50$ $(\mathrm{kg} / \mathrm{sec})$ of this model corresponds approximately to $\mathrm{M} \approx 2$.

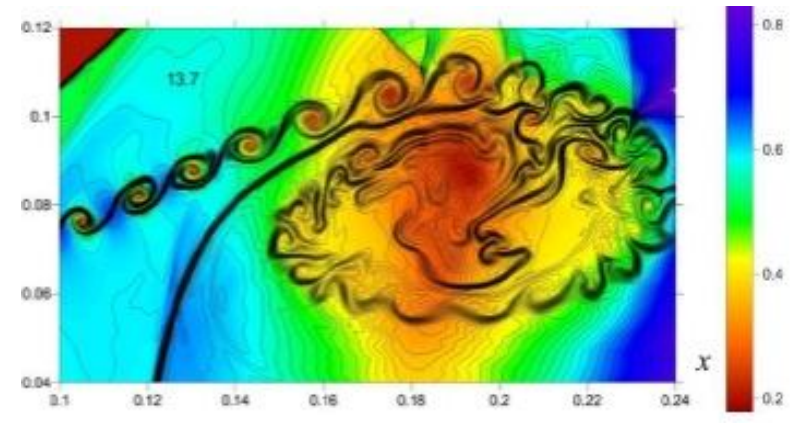

Figure 6a: Reference O. Azarova supersonic vortex [5]

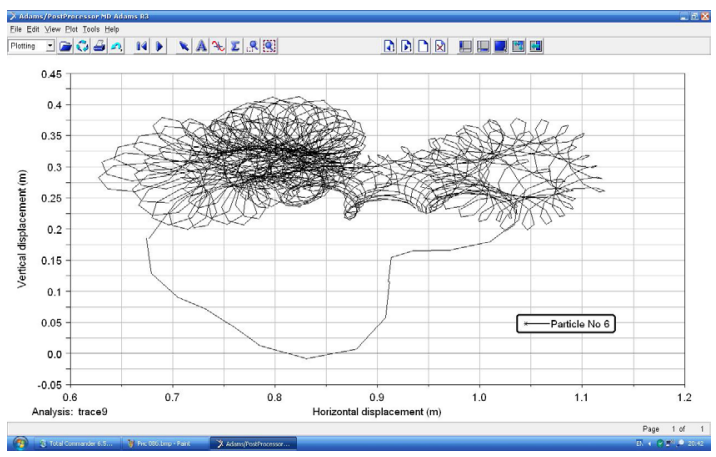

Figure 6b: Particle No.6, $a=50(\mathrm{~kg} / \mathrm{sec})$

\section{FORCE CHARACTERISTIC OF THE GAS GYRO-PARTICLE}

Interactions of the gas gyro-particles with each other and interactions of the gas gyroparticles with the structural ones are determined by the repulsion-type force characteristic. Each gas particle repels each one. The force characteristic is the two-particles interaction force depending on the distance between them. It is approximated by the non-positive segment of the shifted parabola:

$$
F_{i j}\left(d_{i j}\right)=k_{i j}\left(1 / d_{2}-1 / d_{i j}\right), i \neq j
$$

If $d_{i j}<d_{2}$, then $F_{i j}<0$. If $d_{i j} \geq d_{2}$, then $F_{i j}=0$;

where:

$k_{i j}$ - is the compressibility factor; $d_{i j}=\sqrt{\left(x_{j}-x_{i}\right)^{2}+\left(y_{j}-y_{i}\right)^{2}}-$ is the distance between the gyro-particles (subparticles); $d_{2}-$ is the diameter of the particle influence zone. The compressibility factor controls the flow-disturbance propagation velocity. The particles do not interact, if the distance between them exceeds the diameter of the particle influence zone. Initially the particles are packed closely. The step of the particle initial-distribution grid (in the square of the contact-type vortex-induced formation) is equal to $d_{2}$ (see Figure 7).

So, there are 3 structural particles, 16 main gas subparticles and 16 conjugate gas subparticles. The total number of the point masses is $3+16+16=35$. To provide effective computer-program cycling, to simplify the formulae derivation, it is taken that all these elements interact with each other. Only some of the compressibility factors $k_{i j}$ are zeroes. The structural particles interact with the main subparticles only. They do not interact with themselves. They do not interact with the conjugate subparticles. The main subparticles do not interact with themselves. They do not interact with the conjugate subparticles (by the repulstion-type force characterisitic). The conjugate subparticles do not interact with other subparticles at all (by the repulstion-type force characteristic). 
Let $K$ be the matrix of the specified compression factors. It has $35 \times 35=1225$ elements. The factors are entered into the matrix in compliance with the following procedure. At first zero all the matrix elements: $k_{i j}=0 ; i=1, \ldots, 35 ; j=1, \ldots, 35$. Then start to enter non-zero elements. Let $k_{1}$ be the compression factors of the structural particles and the main gas subparticles. Let $k_{2}$ be the compression factors of the main gas subparticles only. So, the $K$ matrix has the following two corresponding blocks. The first block:

$$
k_{i j}=k_{1} ; i=1,2,3 ; j=4, \ldots, 19 ; k_{i j}=k_{1} ; j=1,2,3 ; i=4, \ldots, 19
$$

and the second block:

$$
k_{i j}=k_{2} ; i=4, \ldots, 19 ; j=4, \ldots, 19
$$

The main subparticles do not interact with each other. So, in addition:

$$
k_{j j}=0 ; j=4, \ldots, 19
$$

\section{DYNAMICS EQUATIONS OF VORTEX-INDUCED FORMATION}

The considered equations are nonlinear. The considered aeroelasticity problem is the nonstationary one. The flutter is interpreted as a classic resonance, when the two-mass gas particle pulsation frequency gets into the vicinity of an eigenfrequency of the streamlined elastic body. Friction is not available. These are the $X$-components of the forces applied to the considered 35 point masses:

$$
\begin{gathered}
\ddot{x}_{1}=\left[c_{1}\left(d_{12}-d_{1}\right) \cos \varphi_{12}+c_{1}\left(d_{13}-d_{1}\right) \cos \varphi_{13}+\sum_{j=4}^{19} F_{1 j}\left(d_{1 j}\right) \cos \varphi_{1 j}\right] / m_{1} \\
\ddot{x}_{2}=\left[c_{1}\left(d_{23}-d_{1}\right) \cos \varphi_{23}+c_{1}\left(d_{21}-d_{1}\right) \cos \varphi_{21}+\sum_{j=4}^{19} F_{2 j}\left(d_{2 j}\right) \cos \varphi_{2 j}\right] / m_{1} \\
\ddot{x}_{3}=\left[c_{1}\left(d_{31}-d_{1}\right) \cos \varphi_{31}+c_{1}\left(d_{32}-d_{1}\right) \cos \varphi_{32}+\sum_{j=4}^{19} F_{3 j}\left(d_{3 j}\right) \cos \varphi_{3 j}\right] / m_{1} \\
\ddot{x}_{4}=\left[\begin{array}{c}
\left.c_{2}\left(x_{20}-x_{4}\right)+a \dot{y}_{4}+\sum_{\substack{j=1 \\
j \neq 4}}^{19} F_{4 j}\left(d_{4 j}\right) \cos \varphi_{4 j}\right] / m_{2} \\
\ldots \\
\ddot{x}_{19}=\left[\begin{array}{c}
19 \\
c_{2}\left(x_{35}-x_{19}\right)+a \dot{y}_{19}+\sum_{\substack{j=1 \\
j \neq 19}}^{19} F_{19, j}\left(d_{19, j}\right) \cos \varphi_{19, j} \\
\ddot{x}_{20}=\left[-c_{2}\left(x_{20}-x_{4}\right)+a \dot{y}_{20}\right] / m_{2}
\end{array}\right] / m_{2}
\end{array}\right.
\end{gathered}
$$




$$
\ddot{x}_{35}=\left[-c_{2}\left(x_{35}-x_{19}\right)+a \dot{y}_{35}\right] / m_{2}
$$

where: $\cos \phi_{i j}=\left(x_{j}-x_{i}\right) / d_{i j}$.

The $Y$-components of the forces applied to the considered 35 point masses are much alike.

The initial integration conditions of equations (9) are specified in Figure 7. Initially the two-mass gas gyro-particles are motionless. But the structural particles initially move. $X$ components of their linear velocities are non-zero and equal to $v_{\mathrm{x} 0}$. Actually, the elastic body tries to penetrate through the motionless square-type gas formation at the given speed.

The system of 70 equations (9) is integrated using the 4-th order Runge-Kutta procedure. The equation parameters are: $a=0-5000(\mathrm{~kg} / \mathrm{sec}), m_{1}=50(\mathrm{~kg}), m_{2}=0.5(\mathrm{~kg}), c_{1}=10^{5}(\mathrm{~N} / \mathrm{m})$, $c_{2}=50-50000(\mathrm{~N} / \mathrm{m}), k_{1}=1000(\mathrm{~N} \times \mathrm{m}), k_{2}=10(\mathrm{~N} \times \mathrm{m}), v_{\mathrm{x} 0}=5(\mathrm{~m} / \mathrm{sec})$. Total integration time is $\mathrm{T}=0.4(\mathrm{sec})$. During this time the elastic body penetrates the gas formation completely. The preliminary determined eigenfrequencies of the elastic body (see Figures $4 a-4 b$ ) are: $8.72 \mathrm{~Hz}$, 8.74 Hz, $11.2 \mathrm{~Hz}$.

\section{THE AEROELASTICITY ANALYSIS RESULTS}

The red arrow in Figure 7 specifies the initial $v_{\mathrm{x} 0}$ velocity direction of the streamlined triangular body. Red lines are the trajectories of its structural particles. The elastic body moves into the motionless $1 \times 1\left(\mathrm{~m}^{2}\right)$ square contact-type vortex-induced formation. This

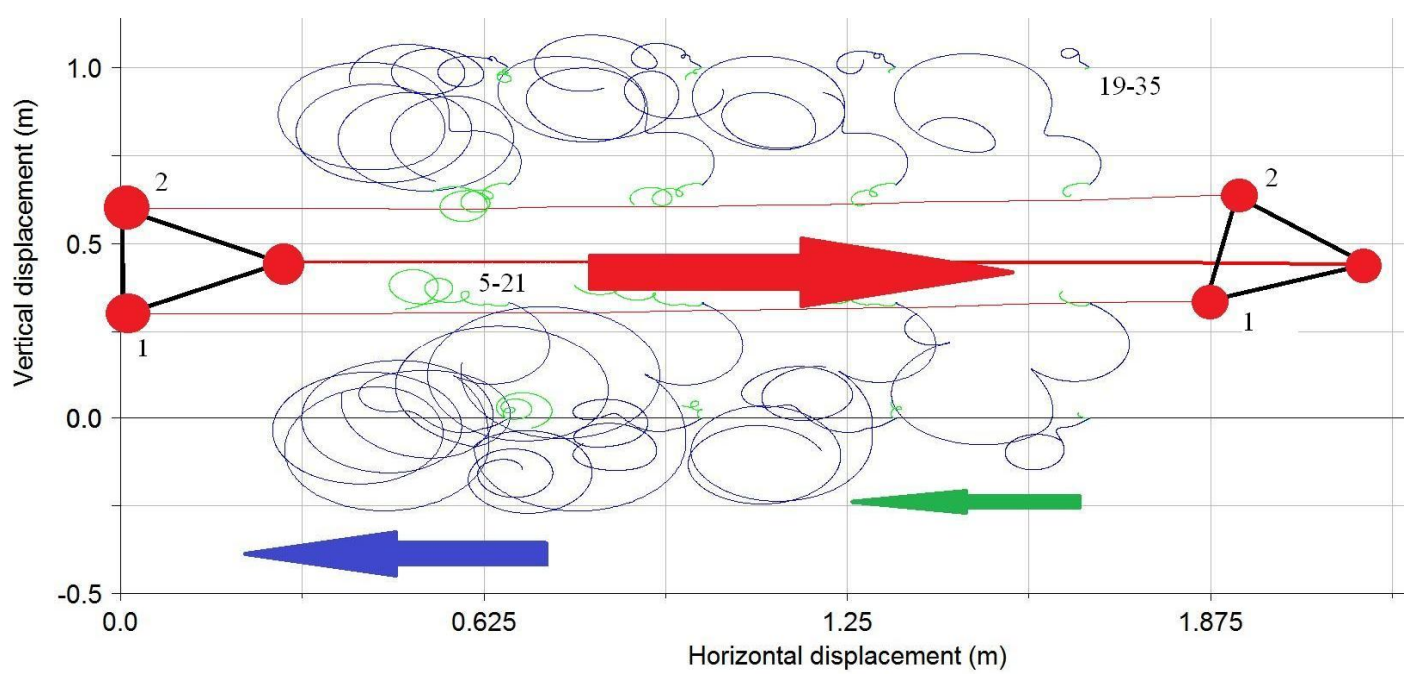

Figure 7: The triangle elastic body penetrates through the contact-type vortex-induced formation

square-shape formation is occupied with 16 two-mass gas gyro-particles. Their initial distribution grid is uniform, $d_{2}-$ is the grid step. It is assumed that supersonic character of the incident flow is determined not by the body linear velocity, but by gas particle rotation intensity (by the gyro-load $a$ parameter). Initially all the gas gyro-particles are motionless, but they are spinned up strongly. The gyro-loads are applied, $a \neq 0$. Rotation intensity of all the particles is the same. If the gyro-particles are arranged from the opposite sides of the streamlined body, then they are spinned up in different directions. Gyro-load parameter of the 
upper particles is positive, gyro-load parameter of the lower particles is negative.

Trajectories of the main subparticles are blue. Trajectories of the conjugate subparticles are green. The main trajectory and the conjugate trajectory of the two mass particle start from the same point at the initial time moment. Figure 7 is overloaded. So, not all the particles are numbered. The numbering scheme is: 1) 3 structural particles Nos. (red trajectories) are from 1 to 3, 2) 16 main subparticles Nos. (blue trajectories) are from 4 to 19, 3) 16 conjugate subparticles Nos. (green trajectories) are from 20 to 35. So (see Figure 7), designation 5-21 specified the initial positions of the main subparticle No.5 and its conjugate particle No.21. Note that the applied gyro-loads carry the gas particles down the flow (see the green arrow and the blue arrow at the bottom of Figure 7). The disturbances do not go up the flow. This effect characterises the supersonic nature of the model. It is seen in Figure 7 that the elastic body (in the right) has already penetrated through the gas formation, but motion of the 19-35 gyro-particle has hardly started. In other words, the elastic-body motion velocity exceeds the flow-disturbance propagation velocity.

Traditionally [13] flutter is considered as a solution of the corresponding boundary problem. Unlike the traditional approach in this report flutter is a resonance. Increase of the gyro-load a parameter (gas particle rotation intensity) provides the gas gyro-particle eigenfrequency splitting (see Figure 3). These are the pulsation frequencies of the gasparticle. The resonance takes place when a flow pulsation frequency gets into the vicinity of an eigenfrequency of the elastic body.

Figure 8 specifies the surge of amplitude of relative displacements $y_{2}-y_{1}-d_{1}$ of the structural particles in the gyro-load $a$ parameter interval from 30 to $40(\mathrm{~kg} / \mathrm{sec})$.

It is shown in Figure 2, that for $a=35.05(\mathrm{~kg} / \mathrm{sec})$ the gas particle pulsation frequency is $11.79(\mathrm{~Hz})$. Figure $4 b$ specifies the $11.2(\mathrm{~Hz})$ elastic-body eigenmode. So, it is the resonance, because the gas pulsation frequency has got into the vicinity of the elastic-body eigenvalue.

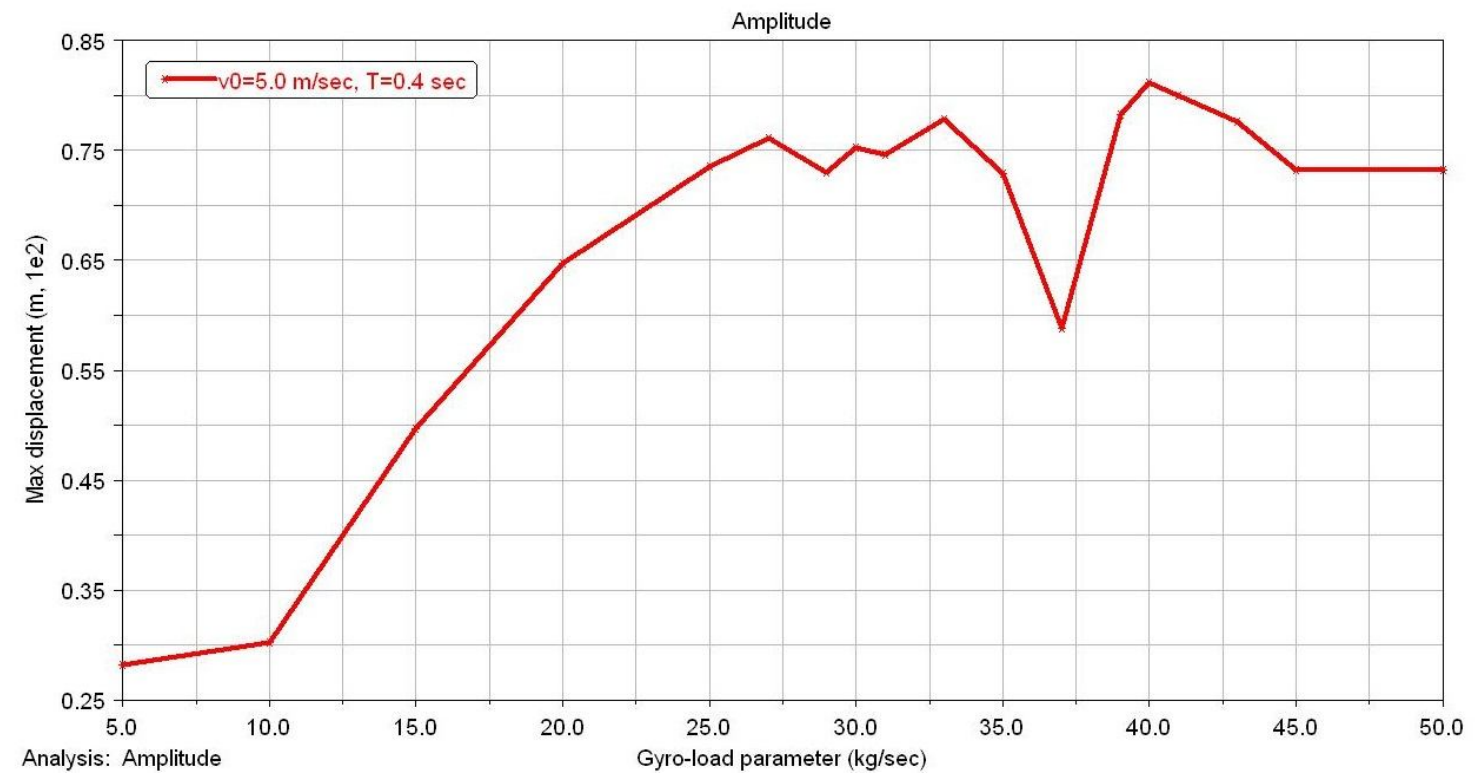

Figure 8: Resonance (flutter) of the streamlined elastic body 


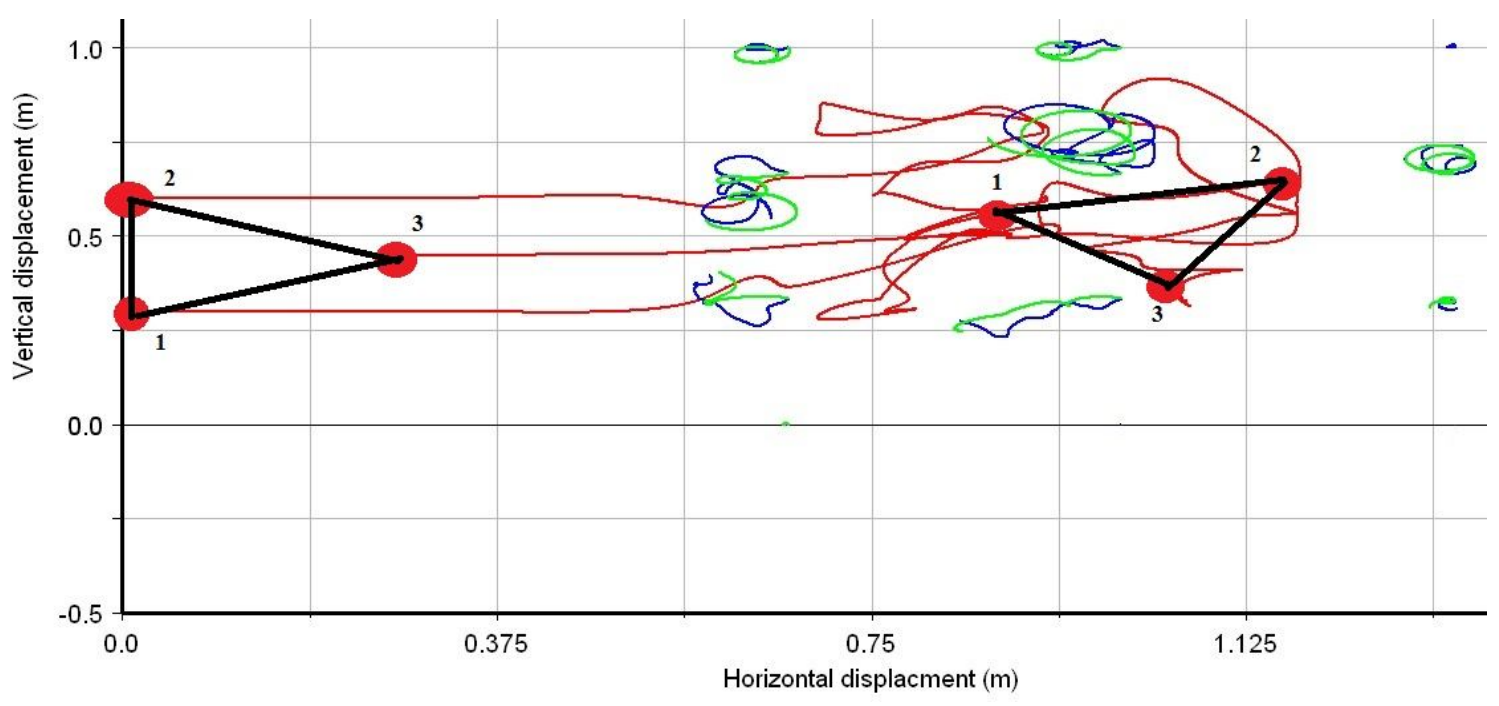

Figure 9: Quarter turn (divergence) of the streamlined elastic body, $a=5000(\mathrm{~kg} / \mathrm{sec})$

Note that further increase of the gyro-load $a$ parameter (gas-particle rotation intensity) is accompanied with growth of aerodynamic drag. Figure 9 illustrates the case, when $a$ is high enough. In this case, the streamlined body runs against the contact-type vortex-induced formation, oscillates chaotically and makes a counter-clockwise quarter turn. This is the aeroelastic divergence.

\section{CONCLUSIONS}

- The two-mass gyro-particle is proposed as the tool for modeling the plasmacontaining supersonic flow. This particle can be divided in two oppositely-charged single gyro-particles and thus ionize the incident flow. Plasma is not considered here. This work is only a preparation step in this direction.

- It is shown that the supersonic flow character may be determined not by linear velocity of the streamlined body, but by rotation intensity of the incident gas gyroparticles.

\section{REFERENCES}

[1] T.A. Lapushkina, A.V. Erofeev, O.A. Azarova, O.V. Kravchenko. Interaction of a plane shock wave with an area of ionization instability of discharge plasma in air. Aerospace Science and Technology (2019)85:347-358.

[2] Артеха С.Н. Определение параметров плазмы с учетом локальных вращений. Russian Federation, Журнал технической физики (2011), Vol. 81, 1:65-68.

[3] Булгаков В.Н., Котенев В.П., Сапожников Д.А. Моделирование сверхзвукового обтекания затупленных конусов с учетом разрыва кривизны образующей тела. Russian Federation, Математическое моделирование и численные методы (2017)2:81-91. 
[4] Котенев В.П., Сысенко В.А. Аналитические формулы повышенной точности для расчета распределения давления на поверхности выпуклых, затупленных тел вращения произвольного очертания. Russian Federation, Mатематическое моделирование и численные методы (2014)1:68-81.

[5] Азарова О.А. Неустойчивости и контактно-вихревые структуры в задачах сверхзвукового обтекания с внешними источниками энергии. Диссертация на соискание ученой степени доктора физико-математических наук по специальности 01.02 .05 «Механика жидкости, газа и плазмы». Москва, (2012).

[6] Борисов В.Е., Давыдов А.А., Константиновская Т.В., Луцкий А.Е., Шевченко А.М., Шмаков А.С. Моделирование сверхзвукового течения в следе за крылом при M=2-4. Russian Federation, Препринты ИПМ им. М.В. Келдыша (2018)50:1-19.

DOI: 10.20948/prepr-2018-50, URL: http://library.keldysh.ru/preprint.asp?id=2018-50.

[7] Ватрухин Ю.М., Мензульский С.Ю., Никопоренко А.В. Определение аэроупругих характеристик гиперзвукового летательного аппарата с точки зрения безопасности авиаперевозок. Russian Federation, Специальная техника (2010)4:41-46.

[8] Мезульский С.Ю. Методика расчета динамических аэроупругих характеристик конструкции, обтекаемой гиперзвуковым потоком воздуха. Russian Federation, Известия ВУЗов, Машиностроение (2011)2:16-22

[9] B.J. Thuruthimattan, P.P. Friedmann, J.J. McNamara, and K.G. Powell. Aeroelasticity of a generic hypersonic vehicle. Proceedings of the 43d AIAA/ASME/ASCE/AHS/ASC Structures, Structural Dynamics and Materials Conference. Denver, Colorado, (22-25 April 2002):1-14

[10] Щеглов Г.А., Коцур О.С. Реализация метода обмена интенсивностями вортонотрезков для учета вязкости в методе вихревых элементов. Russian Federation, Вестник МГТУ имени Н.Э. Баумана, Естественные науки (2018)3:48-67.

DOI: $10.18698 / 1812-3368-2018-3-48-67$, http://vestniken.ru/catal...th/compmath/818.html

[11] Щеглов Г.А., Марчевский И.К. Моделирование эволюции переплетенных вихревых нитей методом вихревых элементов. Russian Federation, Известия Российской Академии Наук, Механика твердого тела (2016)3:131-139.

[12] Marchevskii I.K., Shcheglov G.A. On the dynamic stability of an elastically fixed high-drag airfoil under vortical parametric excitations // Mechanics of solids (2016), Vol. 51, 1:165-176.

DOI: 10.3103/S0025654416030122, http://link.springer.com/...\%2FS0025654416030122

[13] Аринчев С.В. Теория колебаний неконсервативных систем. Moscow, Publishing House of Bauman Moscow State Technical University, (2002).

[14] Sergey V. Arinchev. Simulation of reversed torsion of the AlMg6 aluminium bar using the macro-molecule approach. International Center for Numerical Methods in Engineering (CIMNE), Proceedings of the XIII International Conference on Computational Plasticity. Fundamentals and Applications, COMPLAS XIII, Polytechnic University of Catalonia (UPC), Barcelona, Spain, 1-3 Septemper 2015, EbookComplas 2015, (2015):429-439.

http://congress.cimne.com/complas2015/frontal/default.asp 
[15] Sergey V. Arinchev. Back from the solid temperature to kinetic energy of its macromolecules. International Center for Numerical Methods in Engineering (CIMNE), Proceedings of the IV-th International Conference on Particle-Based Methods. Fundamentals and Applications. Polytechnic University of Catalonia (UPC), Barcelona, Spain 28-30 September, 2015, E-book_PARTICLES_2015,(2015):909-920.

http://congress.cimne.com/particles2015/frontal/doc/E-book_PARTICLES 2015.pdf 